\title{
Evaluating clinical periodontal measures as surrogates for bacterial exposure: The Oral Infections and Vascular Disease Epidemiology Study (INVEST)
}

\author{
Ryan T Demmer', Panos N Papapanou ${ }^{2}$, David R Jacobs Jr, ${ }^{3,4}$, Moïse Desvarieux ${ }^{1,5,6^{*}}$
}

\begin{abstract}
Background: Epidemiologic studies of periodontal infection as a risk factor for cardiovascular disease often use clinical periodontal measures as a surrogate for the underlying bacterial exposure of interest. There are currently no methodological studies evaluating which clinical periodontal measures best reflect the levels of subgingival bacterial colonization in population-based settings. We investigated the characteristics of clinical periodontal definitions that were most representative of exposure to bacterial species that are believed to be either markers, or themselves etiologic, of periodontal disease.

Methods: 706 men and women aged $\geq 55$ years, residing in northern Manhattan were enrolled. Using DNA-DNA checkerboard hybridization in subgingival biofilms, standardized values for Aggregatibacter actinomycetemcomitans, Porphyromonas gingivalis, Treponema denticola and Tannerella forsythia were averaged within mouth and summed to define "bacterial burden". Correlations of bacterial burden with clinical periodontal constructs defined by the severity and extent of attachment loss (AL), pocket depth (PD) and bleeding on probing (BOP) were assessed.

Results: Clinical periodontal constructs demonstrating the highest correlations with bacterial burden were: i) percent of sites with BOP ( $r=0.62)$; ii) percent of sites with PD $\geq 3 \mathrm{~mm}(r=0.61)$; and iii) number of sites with $\mathrm{BOP}(r=0.59)$. Increasing PD or AL severity thresholds consistently attenuated correlations, i.e., the correlation of bacterial burden with the percent of sites with $P D \geq 8 \mathrm{~mm}$ was only $r=0.16$.

Conclusions: Clinical exposure definitions of periodontal disease should incorporate relatively shallow pockets to best reflect whole mouth exposure to bacterial burden.
\end{abstract}

\section{Background}

There are several models for studying infectious origins of cardiovascular disease(CVD) [1]. Many models rely on serum antibody titer to define infectious exposure. This has the advantage of capturing historical infectious exposure, but the possible disadvantage of not requiring the presence of active infection at the time of measurement. Another method of assessing infectious bacterial exposure is to directly measure bacterial colonization levels. In this regard, one infection model that may be useful is periodontal disease, because active bacterial

\footnotetext{
* Correspondence: md108@columbia.edu

'Department of Epidemiology, Mailman School of Public Health, Columbia University, New York, NY, USA
}

infections with inflammatory consequences are often present for years and are easily accessible in the subgingiva[2-5].

However, microbiological assessment is resource intensive and is rarely done in epidemiologic studies investigating periodontal-CVD associations. Consequently, studies exploring associations between periodontal infection and CVD frequently use one of a wide variety of whole mouth summaries of clinical periodontal measures (i.e. pocket depth, attachment loss and bleeding on probing) as a surrogate measure of underlying microbiology. Methodological research is needed to clarify which clinical periodontal constructs act as surrogates for such bacterial infection. In doing so, hypothesis

\section{() Biomed Central}


testing in future studies can be more specifically focused on infectious exposure as opposed to clinical periodontal characteristics which can be the result of non-infectious exposures such as smoking[6-8], diabetes[9], or endodontic lesions[10].

In this paper we investigated how well whole mouth clinical periodontal constructs reflect exposure to bacteria that are associated with risk of periodontal disease.

\section{Methods}

The Oral Infections and Vascular Disease Epidemiology Study (INVEST) is a randomly sampled prospective population-based cohort study investigating whether oral infections increase the risk of carotid atherosclerosis and stroke[11]. Briefly, 1056 subjects were randomly selected from Northern Manhattan, an area between $145^{\text {th }}$ Street and $218^{\text {th }}$ Street, bordered westward by the Hudson River, and separated eastward from the Bronx by the Harlem River. Hispanics, Blacks, and Whites live together in this area and have similar access to medical care. The selection process was derived from the Northern Manhattan Study (NOMAS) in which patients are also enrolled[12].

Of 841 dentate participants enrolled at baseline, both clinical periodontal exams and subgingival plaque samples were available for 706 subjects, who entered these analyses.

The Institutional Review Board at Columbia University approved the study, and all subjects provided informed consent.

\section{Dental history and oral examination}

Subjects were interviewed and examined by trained research assistants and calibrated dental examiners $[4,11]$. Teeth were counted and localized. Plaque samples in the two most posterior teeth (mesiolingual in the upper jaw and mesiobuccal in the lower jaw) were collected before probing. Assessment of periodontal status for all teeth present included presence/absence of dental plaque, probing depth in millimeters, and location of the gingival margin in relation to the cementoenamel junction at six locations for each tooth (mesiobuccal, midbuccal, distobuccal, mesiolingual, midlingual and distolingual) using a UNC-15 manual probe with ruler markings at each millimeter from 1 to 12 (HuFriedy, Chicago, IL). Attachment loss was calculated as the sum of pocket depth and gingival margin.

Subgingival plaque collection and laboratory processing A maximum of eight subgingival plaque samples (mean 7; median 8) were collected from each subject by a single scaling stroke from the base of the periodontal pocket using a sterile Gracey curette. Samples were collected from the two most posterior teeth in each quadrant (mesiopalatal sites in the maxilla and mesiobuccal sites in the mandible). The collected plaque mass from each site was transferred into an individual Eppendorf tube containing $200 \mu \mathrm{l}$ of sterile $\mathrm{T}$-E buffer $(10 \mathrm{mM}$ Tris $\mathrm{HCl}, 1.0 \mathrm{~mm}$ EDTA, $\mathrm{pH}$ 7.6). The tubes were immediately transferred into the laboratory and the plaque pellet was re-suspended, vigorously vortexed, and $200 \mu \mathrm{l}$ of a $0.5 \mathrm{M} \mathrm{NaOH}$ solution were added. The samples were kept at $+4^{\circ} \mathrm{C}$ until immobilization onto nylon membranes, within a few days from sample collection.

A total of 4,922 bacterial plaque samples (collected from $\mathrm{n}=706$ participants) are included presently.

Four bacterial species (Aggregatibacter actinomycetemcomitans, Porphyromonas gingivalis, Tannerella forsythia and Treponema denticola) were assessed from each subgingival plaque sample using checkerboard DNA-DNA hybridization as previously described $[4,13]$. These 4 species were selected because there is strong evidence that they are either markers of, or themselves causal agents for, periodontal disease $[4,13]$.

\section{Statistical analysis}

All analyses were performed in PC-SAS for Windows 9.1 and R for Windows 2.2.1.

Creation of Bacterial Burden: Laboratory analysis provides a relative quantity of individual bacterial species for each subgingival plaque sample by comparison to known standards; these distributions are strongly skewed towards larger values and it is not known whether absolute amounts of different species are comparable. Bacterial values were therefore averaged within mouth, natural log transformed and standardized by dividing each respective natural log transformed bacterial value by the population standard deviation for the respective species. One standard deviation on the log scale was treated as equivalent across bacteria. For each person, exposure to periodontal bacteria was quantified by summing the standardized values for the four bacteria A. actinomycetemcomitans, $P$. gingivalis, T. forsythia and T. denticola to create a bacterial burden (BB) score[4]. Bacterial burden scores are presented in standard deviation units (SDU).

\section{Creation of Whole Mouth Clinical Periodontal Constructs}

We created a series of summary clinical periodontal constructs[14] reflecting both the extent and severity of current periodontal disease (as measured by PD and $\mathrm{BOP}$ ) and the past cumulative experience to periodontitis (as measured by AL). The terms "extent" and "severity" were adapted from the method reported by Carlos et al. in defining the extent and severity index (ESI)[15]. Constructs based on a combination of extent and severity We considered severity thresholds of $2-8 \mathrm{~mm}$ for PD or AL. For each severity threshold, disease extent was defined by various metrics yielding multiple constructs based on a combination of extent and severity of clinical periodontal disease as follows: 1) number of sites with $\mathrm{PD}$ or $\mathrm{AL} \geq$ specified severity thresholds; 2) percent of 
sites with $\mathrm{PD}$ or $\mathrm{AL} \geq$ specified severity thresholds; 3 ) sum of PD or AL beyond the specified severity thresholds; 4) mean PD or AL beyond specified severity thresholds; 5) number of sites with PD or AL equal to specified severity thresholds; 6) percent of sites with PD or AL equal to specified severity thresholds. We also created the aforementioned constructs using only periodontal measurements taken from interproximal sites.

\section{Definitions based on extent only}

The overall mean PD and AL allowed clinical measures from all sites to directly contribute information regarding periodontal disease. Likewise, for BOP we calculated the number and percent of measured sites that bled on probing.

\section{Post hoc Definitions}

Based on the findings from the aforementioned definitions, we created a post hoc periodontal definition based on a site by site combination of bleeding on probing status and whether or not the pocket was $\geq 3 \mathrm{~mm}$ as follows: i) sites with $\mathrm{PD} \leq 3 \mathrm{~mm}$ received a value $=0$ (regardless of bleeding status); ii) sites with $\mathrm{PD} \geq 3$ and no $\mathrm{BOP}$ received a value $=1$; iii) sites with $\mathrm{PD} \geq 3$ and $\mathrm{BOP}$ received a value $=2$. Finally, we took the whole mouth average of these values to represent the individual. The purpose of this definition was to see if the combination of information from two variables could enhance observed associations between clinical periodontal definitions and bacterial burden.

Correlations were run between all candidate periodontal variables and the dependent variable "bacterial burden". We tested statistical significance of differences in correlations among the periodontal constructs using the "compOverlapCorr" package in R (developed by $\mathrm{Li}$ and Zhu, 2006; see $R$ user's manual). This is based on a method for comparing correlated correlations between variables $(\mathrm{Y}, \mathrm{X} 1)$ and $(\mathrm{Y}, \mathrm{X} 2)$, described by Meng et al [16]. The correlations are correlated because of a shared dependent variable, $\mathrm{Y}$, as well as a correlation between $\mathrm{X} 1$ and $\mathrm{X} 2$. The algebraic formula for the $\mathrm{Z}$ test comparing the difference between two sample correlation coefficients (i.e., $r_{Y, X 1}$ and $\left.r_{Y, X 2}\right)$, follows: $\left(z_{r 1}-z_{r}\right) *$ *square root of $\left((\mathrm{N}-3) /\left(2\left(1-r_{\mathrm{x}}\right) h\right)\right)$, where $\mathrm{N}=$ sample size; $\mathrm{z}_{\mathrm{ri}}$ is the Fisher $\mathrm{z}$-transformed $\mathrm{r}_{\mathrm{Y}, \mathrm{Xi}} ; \mathrm{r}_{\mathrm{x}}$ is the correlation between the two predictor variables $\mathrm{X} 1$ and $\mathrm{X} 2 ; \mathrm{r}^{2}{ }_{1,2}$ mean $=\left(\mathrm{r}^{2}{ }_{\mathrm{Y}, \mathrm{X} 1}+\mathrm{r}^{2}{ }_{\mathrm{Y}, \mathrm{X} 2}\right) / 2, \mathrm{~h}=1-\mathrm{f}\left(\mathrm{r}^{2}{ }_{1,2}\right.$ mean $) /\left(1-\mathrm{r}^{2}{ }_{1,2}\right.$ mean $) ; \mathrm{f}=\left(1-\mathrm{r}_{\mathrm{x}}\right) /\left(2\left(1-\mathrm{r}_{1,2}^{2}\right.\right.$ mean $\left.)\right)$ which was required to be $\leq 1$. This formulation shows that statistical significance of differences between two correlation coefficients $r_{Y, X 1}$ and $r_{Y, X 2}$ depends strongly on the correlation between the two periodontal constructs being compared $\mathrm{r}_{\mathrm{X} 1, \mathrm{X} 2}$.

All analyses were conducted among subgroups according to either smoking status, diabetes status or gender to inform the potential for effect modification or confounding. This analysis is methodological as opposed to etiological in nature. Therefore, we present $\mathrm{p}$-values for the reader's information but encourage the reader to consider the overall trends as opposed to any specific tests of statistical significance as these p-values are not adjusted for multiple comparisons and the data are observational.

\section{Results}

INVEST participants are tri-ethnic (57\% Hispanic, 23\% Black and 20\% White) with an average age \pm SD of $69 \pm$ 9 years. Women comprise $60 \%$ of this sample and on average participants have lost $14 \pm 8$ teeth (including $3^{\text {rd }}$ molars).

Bacterial burden was normally distributed with mean \pm SD of $32 \pm 4$ SDU. Summary clinical periodontal definitions became highly skewed with increasing severity thresholds because few participants exhibited high AL or deep PD (Table 1). For example, 99\% of participants had at least one periodontal site with a PD $\geq 3 \mathrm{~mm}$ while only $11 \%$ had at least one site with $P D \geq 8 \mathrm{~mm}$. Among the $89 \%$ of participants with no PD sites $\geq 8$ $\mathrm{mm}$ substantial variation in periodontal status remained; the number of sites with $\mathrm{PD} \geq 3 \mathrm{~mm}$ ranged from $0-150$ (median $=32$ ) and the percent of sites with $\mathrm{PD} \geq 3 \mathrm{~mm}$ ranged from $0 \%-97 \%$ (median $=36 \%$ ).

Clinical periodontal definitions showed a wide range of correlations with one another. Definitions utilizing similar extent or severity criteria were highly correlated. For example, definitions summarizing the percent of sites with $\mathrm{PD} \geq 4$ or $5 \mathrm{~mm}$ had a correlation of $\mathrm{r}=0.90$, while the percent of sites with PD $\geq 2$ or $8 \mathrm{~mm}$ were only correlated at $r=0.17$. Tables 2 and 3 present correlation matrices for selected periodontal definitions.

Table 1 Distributions for *Selected Clinical Periodontal Constructs $(\mathbf{n}=706)$.

\begin{tabular}{lccccc}
\hline Variable & $\mathbf{2 5}^{\text {th }}$ & Median & Mean & $\mathbf{7 5}^{\text {th }}$ & Std Dev \\
\hline$\% A L \geq 3$ & 28 & 57 & 56 & 86 & 32 \\
$\% A L \geq 6$ & 0 & 3 & 12 & 14 & 19 \\
$\% A L \geq 8$ & 0 & 0 & 3 & 2 & 10 \\
$\% P D \geq 3$ & 19 & 40 & 43 & 67 & 27 \\
$\% P D \geq 6$ & 0 & 0 & 2 & 0 & 6 \\
$\% P D \geq 8$ & 0 & 0 & 0.5 & 0 & 2 \\
\%BOP & 3 & 13 & 33 & 50 & 46 \\
\#BOP & 2 & 11 & 27 & 35 & 36 \\
\hline Abbrevion & & & & & \\
\hline
\end{tabular}

Abbreviations: AL: Attachment loss PD: Pockect depth BOP: bleeding on probing $25^{\text {th }}$ and $75^{\text {th }}$ denote percentiles. $\%$ refers to percent of sites per mouth. \# refers to the number of sites per mouth. *Note, distributional patterns across increasing severity cut points were similar for all clinical periodontal constructs (data not shown). 
Table 2 Correlations between Clinical Periodontal Constructs $(\mathbf{n}=706)$

\begin{tabular}{|c|c|c|c|c|c|c|c|}
\hline & $\% \mathrm{PD} \geq 2$ & $\% \mathrm{PD} \geq 3$ & $\% \mathrm{PD} \geq 4$ & $\% P D \geq 5$ & $\% \mathrm{PD} \geq 6$ & $\% P D \geq 7$ & $\% \mathrm{PD} \geq 8$ \\
\hline$\% \mathrm{PD} \geq 2$ & 1 & 0.78 & 0.51 & 0.39 & 0.26 & 0.19 & 0.17 \\
\hline$\% \mathrm{PD} \geq 3$ & & 1 & 0.76 & 0.62 & 0.43 & 0.33 & 0.29 \\
\hline$\% \mathrm{PD} \geq 4$ & & & 1 & 0.88 & 0.69 & 0.58 & 0.51 \\
\hline$\% \mathrm{PD} \geq 5$ & & & & 1 & 0.86 & 0.75 & 0.67 \\
\hline$\% P D \geq 6$ & & & & & 1 & 0.92 & 0.81 \\
\hline$\% P D \geq 7$ & & & & & & 1 & 0.84 \\
\hline$\% \mathrm{PD} \geq 8$ & & & & & & & 1 \\
\hline
\end{tabular}

Correlations between selected clinical periodontal constructs holding extent definition (percent of sites with pocket depth) constant and allowing the severity threshold to vary.

Correlations between bacterial burden and several clinical periodontal definitions are shown in Table 4. The strongest correlations were observed for percent of sites bleeding on probing $(r=0.62)$, percent of sites with $P D \geq$ $3 \mathrm{~mm}(\mathrm{r}=0.61)$ and number of sites bleeding on probing $(\mathrm{r}=0.59)$. Pair-wise comparisons showed no statistically significant differences between any of these three correlation coefficients (all p > 0.10). Comparisons between correlations for any of these three definitions and any other whole-mouth definition in this analysis yielded a p-value of $<0.05$. The highest correlation involving AL was 0.48. The post hoc definition representing a combination of $\mathrm{PD} \geq 3$ and presence of BOP yielded a marginally stronger correlation with bacterial burden $(r=0.64)$.

Results were not meaningfully different among subgroups according to either gender, smoking status or diabetes status.

When using periodontal constructs based on only interproximal periodontal measurements, the results were very similar to those shown in Table 4 . For example, the correlation between bacterial burden and the percent of sites with interproximal $\mathrm{PD} \geq 3 \mathrm{~mm}$ was 0.62 while the correlation for the percent of sites with interproximal $\mathrm{PD} \geq 8 \mathrm{~mm}$ was 0.15 .

Among the definitions that incorporated both severity and extent of clinical periodontal disease, the strongest correlations were observed when severity thresholds in the $2-4 \mathrm{~mm}$ range were considered (Table 4). It may be appropriate, however, to omit the $2 \mathrm{~mm}$ sites, themselves. When considering correlations between bacteria burden and the number or percent of sites equal to selected severity criteria, there was a clear demarcation between 2 and $3 \mathrm{~mm}$ probing depth or attachment loss. All definitions utilizing a $2 \mathrm{~mm}$ criterion were inversely related to bacterial burden, for example having a high percent of sites with $\mathrm{PD}=2 \mathrm{~mm}$ was suggestive of low bacterial burden $(r=-0.55)$, whereas having a high percent of sites with $\mathrm{PD}=3 \mathrm{~mm}$ was suggestive of high bacterial burden $(r=0.54)$.

Both mean AL $(r=0.41)$ and mean PD $(r=0.52)$ were also strongly correlated with bacteria burden.

\section{Discussion}

These data demonstrate strong positive associations between several whole mouth clinical periodontal constructs and periodontal bacterial burden. Bacterial burden represents the combined colonization level of four periodontal microbes (A. actinomycetemcomitans, $P$. gingivalis, $T$. denticola and $T$. forsythia) believed to either cause periodontal disease directly, or to correlate strongly with as yet unidentified causative bacteria [17]. The highest correlations with bacterial burden were

Table 3 Correlations between Clinical Periodontal Constructs $(\mathbf{n}=706)$

\begin{tabular}{lllllllll}
\hline & \#PD $\geq 3$ & \%PD $\geq 3$ & Mean PD $\geq 3$ & Sum PD $\geq 3$ & \#AL $\geq 3$ & \%AL $\geq 3$ & MeanAL $\geq 3$ & Sum AL $\geq 3$ \\
\hline \#PD $\geq 3$ & 1 & 0.68 & 0.34 & 0.90 & 0.80 & 0.34 & 0.04 & 0.67 \\
\%PD $\geq 3$ & 1 & 0.53 & 0.70 & 0.51 & 0.72 & 0.48 & 0.60 \\
Mean PD $\geq 3$ & & & 1 & 0.63 & 0.23 & 0.32 & 0.56 & 0.48 \\
Sum PD $\geq 3$ & & & & 1 & 0.71 & 0.38 & 0.25 & 0.80 \\
\#AL $\geq 3$ & & & & 1 & 0.55 & 0.09 & 0.84 \\
\%AL $\geq 3$ & & & & & 1 & 0.58 & 0.64 \\
Mean AL $\geq 3$ & & & & & & & 1 & 0.49 \\
Sum AL $\geq 3$ & & & & & & & & 1 \\
\hline
\end{tabular}

Correlations between selected clinical periodontal constructs, holding severity threshold constant and allowing the extent definition to vary.

\# refers to number of sites/mouth beyond $3 \mathrm{~mm}$ severity threshold.

$\%$ refers to percent of sites/mouth beyond $3 \mathrm{~mm}$ severity threshold.

Mean refers to mean pocket depth among sites $\geq 3 \mathrm{~mm}$ severity threshold.

Sum refers to cumulative pocket depth among sites $\geq 3 \mathrm{~mm}$ severity threshold. 
Table 4 Correlations between Bacterial Burden and Selected Clinical Periodontal Constructs $(\mathbf{n}=\mathbf{7 0 6})$

\begin{tabular}{|c|c|c|c|c|c|c|c|c|}
\hline \multirow[b]{2}{*}{$\begin{array}{l}\text { Severity } \\
\text { Threshold }\end{array}$} & \multicolumn{4}{|c|}{ Attachment Loss Extent Constructs } & \multicolumn{4}{|c|}{ Pocket Depth Extent Constructs } \\
\hline & $\begin{array}{c}\# A L \geq \\
\text { Threshold }\end{array}$ & $\begin{array}{c}\% A L \geq \\
\text { Threshold }\end{array}$ & $\begin{array}{l}\text { Sum } A L \geq \\
\text { Threshold }\end{array}$ & $\begin{array}{l}\text { Mean } \mathrm{AL} \geq \\
\text { Threshold }\end{array}$ & $\begin{array}{c}\# P D \geq \\
\text { Threshold }\end{array}$ & $\begin{array}{c}\% \mathrm{PD} \geq \\
\text { Threshold }\end{array}$ & $\begin{array}{l}\text { Sum } P D \geq \\
\text { Threshold }\end{array}$ & $\begin{array}{c}\text { Mean PD } \geq \\
\text { Threshold }\end{array}$ \\
\hline $2 \mathrm{~mm}$ & $0.39(A, C)$ & $0.48(\mathrm{~A})$ & $0.47(A)$ & $0.30(\mathrm{~A})$ & $0.16(A, E, F)$ & $0.42(\mathrm{~A})$ & $0.40(A, C)$ & $0.49(\mathrm{~A})$ \\
\hline $3 \mathrm{~mm}$ & $0.48(B)$ & $0.48(\mathrm{~A})$ & $0.46(A)$ & $0.21(\mathrm{~B})$ & $0.51(B)$ & $0.61(\mathrm{~B})$ & $0.48(B)$ & $0.25(B, D)$ \\
\hline $4 \mathrm{~mm}$ & $0.40(A)$ & $0.30(B)$ & $0.38(B)$ & $0.27(\mathrm{~A})$ & $0.39(C)$ & $0.39(\mathrm{~A})$ & $0.39(A)$ & $0.34(\mathrm{C})$ \\
\hline $5 \mathrm{~mm}$ & $0.39(A)$ & 0.29 (B) & $0.34(C)$ & $0.23(\mathrm{~B})$ & 0.39 (C) & $0.38(\mathrm{~A})$ & $0.35(C)$ & $0.28(D)$ \\
\hline $6 \mathrm{~mm}$ & $0.33(C)$ & $0.26(B)$ & 0.29 (D) & $0.25(B)$ & $0.28(D)$ & $0.26(C)$ & $0.24(D)$ & $0.27(\mathrm{D})$ \\
\hline $7 \mathrm{~mm}$ & $0.29(D)$ & $0.23(\mathrm{C})$ & $0.25(E)$ & $0.26(A, B)$ & $0.18(E)$ & $0.20(\mathrm{D})$ & 0.19 (E) & $0.18(\mathrm{E})$ \\
\hline $8 \mathrm{~mm}$ & $0.28(D)$ & $0.24(B, C)$ & $0.23(F)$ & $0.24(A, B)$ & $0.14(F)$ & $0.16(\mathrm{D})$ & $0.15(F)$ & $0.15(\mathrm{E})$ \\
\hline
\end{tabular}

Bacterial burden is the dependent variable for all 56 correlations presented. All 56 correlation coefficients are statistically significantly different than zero (p-value $<0.0001$ for null hypothesis Ho: $\rho=0$ ). Pairwise comparisons were performed between all seven correlation coefficients within each extent periodontal construct (represented in columns), to see if severity threshold impacted strength of correlation (Ho: $\rho_{1 i}=\rho_{2 i}$ ); coefficients that do not share a common letter are statistically significantly different $(p<0.05)$ - based on methods for comparing correlated correlation coefficients from Meng et al.(Meng et al. 1992) For example, the correlation between bacterial burden (the common dependent variable) and $\% \mathrm{PD} \geq 3 \mathrm{~mm}(r=0.61)$ is statistically significantly different than the correlation between bacterial burden and $\% \mathrm{PD} \geq 4 \mathrm{~mm}(r=0.39)$.

consistently observed among the summary clinical constructs utilizing low severity thresholds such as the percent of sites with $\mathrm{PD} \geq 3 \mathrm{~mm}$. Bleeding on probing also demonstrated strong positive correlations with bacterial burden.

The observation that clinical constructs utilizing low severity thresholds demonstrated the strongest correlations with bacterial bacteria in this analysis might, at first, appear counterintuitive, since low severity sites are often not regarded as clinical disease. However, these results are not surprising when considering the distributional properties of the clinical constructs utilized presently. We observed that constructs incorporating relatively high severity thresholds demonstrated skewed distributions due to the low prevalence of deep pockets in our cross-sectional epidemiological setting. This low prevalence is potentially due to population characteristics related to access to health care and health behaviors [4]. It is also an expected consequence of severely diseased periodontal sites being predisposed to treatment or removal via tooth loss or extraction. Therefore, in population-based settings such as INVEST, substantial exposure to pathological periodontal microbiology likely occurs in shallow periodontal pockets that do not yet exhibit commonly accepted clinical signs of frank periodontal disease.

This supposition is corroborated by data from other research reports. We have previously found in INVEST, that $77 \%$ of $\sim 5,000$ examined periodontal sites had a pocket depth of $\leq 3 \mathrm{~mm}$ while only $11 \%$ of sites were $\geq$ $5 \mathrm{~mm}[18]$. When considering the $\sim 1200$ periodontal sites with high bacteria burden levels ( $4^{\text {th }}$ quartile), $60 \%$ of these sites had pocket depths of $\leq 3 \mathrm{~mm}[18]$. Likewise, data from a Chinese population demonstrated that only $7.5 \%$ of 1,864 periodontal sites examined had a probing depth of $\geq 5 \mathrm{~mm}$ despite frequent colonization in periodontal sites by species include in our current report[19]. The prevalence of colonization by A actinomycetemcomitans, P. gingivalis, T. denticola and T. forsythia, were $38 \%, 87 \%, 74 \%$ \& $73 \%$ respectively[19]. Similar results have been published from other populations[20,21].

Results of this nature highlight the potential importance of subclinical periodontal infection in the epidemiological context of periodontal infection and cardiovascular disease risk. Relatively shallow periodontal sites not only have the potential to develop gingivitis and subsequent periodontitis but might also be undergoing subclinical pathological processes that could have systemic effects. Therefore some shallow periodontal sites might actually be considered as nascent disease. Accordingly, in INVEST we have reported that the risk of bleeding on probing associated with high levels of bacterial burden was more pronounced in shallow than in deep periodontal pockets[18]. Moreover, recent research has also shown that low threshold definitions of clinical periodontal disease tend to optimize associations with cardiovascular disease biomarkers[14,22] and two recent publications have reported higher levels of selected periodontal bacteria (including those species studied presently) to be associated with either increased carotid artery intima-media thickness (c-IMT)[4] or increased prevalence coronary heart disease[2].

The finding that pocket depth and bleeding on probing definitions performed as well as, and often better than, attachment loss definitions might have been anticipated when considering that pocket depth and bleeding tend to be better markers of current infection while attachment loss better reflects historical disease. Moreover, attachment loss in buccal sites can be the result of trauma and might have diminish associations with bacterial species, although our results were consistent when using only interproximal sites to create our mouth level clinical definitions. 
The definition of a "shallow" periodontal pocket is ambiguous. While the $3 \mathrm{~mm}$ severity threshold emerged as an apparent transition from decreased to increased exposure to bacterial burden in our study population, the specific transition threshold might vary across populations where treatment standards and access to dental care differ or behavioral risk factor distributions (i.e., smoking, diabetes or oral hygiene habits) differ. Nevertheless, the overall trends reported presently are likely robust to changing population dynamics. If the current findings are in fact supported more generally in other populations, these concepts might explain some of the variability in reported measures of association between periodontal infection and systemic diseases.

Collecting plaque samples in only 8 sites per mouth might not have adequately represented the microbial profile of the whole mouth. We minimized this potential bias by always collecting plaque samples from the eight most posterior teeth, rather than from the most clinically diseased teeth. Further, although legitimate debate remains in regard to whether A. actinomycetemcomitans, $P$. gingivalis, $T$. denticola and/or T. forsythia are causal of periodontal disease, our decision to use these species as a surrogate for pathological biofilms was based, $a$ priori, on the 1996 Consensus Report on Periodontal Diseases: Pathogenesis and Microbial Factors[17] which deemed there to be "Strong Evidence for Etiology" in regard to $A$. actinomycetemcomitans, $P$. gingivalis, and T. forsythia (formerly, B. forsythus). Our addition of Treponema denticola to this construct was also a priori and based on the data presented by Socransky et al. in 1998 describing the "Red Complex" in which $T$. denticola covaried strongly with $T$. Forthysia and $P$. gingivalis[21]. Subsequently, a substantial body of evidence has emerged - including data from INVEST([18]) - in support of the concept that, at minimum, these microbes are strong correlates of currently unidentified causal microbiology (for original research see [9,20,21,23-28]; for comprehensive reviews see [29-32]). Therefore, taken together, we believe these species are reasonable epidemiologic markers of pathological biofilms, even if these species themselves are at some point determined to be noncausal of periodontal disease. Nevertheless, any conclusions regarding optimal clinical constructs for use as surrogates of periodontal bacteria are limited to the species collected presently. Another limitation to the generalizability of our study is that very few of our participants have minimal or no periodontal disease (gingivitis or periodontitis).

\section{Conclusions}

These findings have implications for studies that posit periodontal disease as a model for infection induced CVD, but that have not collected data on oral bacterial profiles. While the relative risk for bacterial colonization in deep vs. shallow periodontal pockets is high, the prevalence of deep pockets is often low in epidemiological settings. Therefore, in absolute terms, much of the attributable risk from exposure to pathogenic bacteria would likely occur in relatively shallow periodontal pockets. Specifically, our findings highlight the potential importance of using clinical definitions that include less severe periodontal disease when such disease is viewed as a model of infection in studies of systemic disease risk.

\section{Acknowledgements}

This research is supported by NIH grant R01 DE-13094 (Dr. Desvarieux) and a Chair of Excellence award from the French Agency for Research and the Institut National de la Santé et de la Recherche Médicale to Dr. Desvarieux (R05115DD). Dr. Demmer was a fellow on T32HL-07779 and is currently supported by K99 DE-018739. Dr. Papapanou was partly supported by NIH grants RR025158 (CTSA Award) and DE015649, and by a grant from ColgatePalmolive, NJ, USA. We thank Miriam Herrera-Abreu, Romanita Celenti and Jun Yang for the laboratory analysis of the dental plaque samples; George Loo, Janet DeRosa, Drs. Yira Florez, Mariana Cukier, and Shantanu Lal for their devoted patient care; the entire INVEST staff; and importantly the patients. Patients were seen at the Columbia University General Clinical Research Center, NIH grant 1UL1RR024156-02.

\section{Author details}

'Department of Epidemiology, Mailman School of Public Health, Columbia University, New York, NY, USA. 'Division of Periodontics, Section of Oral and Diagnostic Sciences, College of Dental Medicine, Columbia University, New York, NY, USA. ${ }^{3}$ Division of Epidemiology and Community Health, School of Public Health, University of Minnesota, Minneapolis, MN, USA. ${ }^{4}$ Department of Nutrition, University of Oslo, Oslo, Norway. ${ }^{5}$ INSERM, UMR-S 707, Paris, F75012; Universite Pierre et Marie Curie-Paris6, UMR S 707, Paris, F-75012,

France. ${ }^{6}$ Ecole des hautes etudes en sante publique, Paris et Rennes, France.

\section{Authors' contributions}

RTD participated in study coordination, statistical analysis and drafted the manuscript. PNP participated in study design and coordination and helped to draft the manuscript. DRJ participated in study coordination, statistical analysis and helped to draft the manuscript. MD conceived of the study and obtained funding, participated in its design and coordination and helped to draft the manuscript. All authors read and approved the final manuscript.

\section{Competing interests}

The authors declare that they have no competing interests.

Received: 4 June 2009

Accepted: 7 January 2010 Published: 7 January 2010

\section{References}

1. Danesh J, Wong Y, Ward M, Muir J: Chronic infection with Helicobacter pylori, Chlamydia pneumoniae, or cytomegalovirus: population based study of coronary heart disease. Heart 1999, 81(3):245-247.

2. Spahr A, Klein E, Khuseyinova N, Boeckh C, Muche R, Kunze M, Rothenbacher D, Pezeshki G, Hoffmeister A, Koenig W: Periodontal infections and coronary heart disease: role of periodontal bacteria and importance of total pathogen burden in the Coronary Event and Periodontal Disease (CORODONT) study. Arch Intern Med 2006, 166(5):554559.

3. Fong IW: Infections and their role in atherosclerotic vascular disease. J Am Dent Assoc 2002, 133(Suppl):7S-13S.

4. Desvarieux M, Demmer RT, Rundek T, Boden-Albala B, Jacobs DR, Sacco RL, Papapanou PN: Periodontal microbiota and carotid intima-media thickness: the Oral Infections and Vascular Disease Epidemiology Study (INVEST). Circulation 2005, 111(5):576-582. 
5. Demmer RT, Desvarieux M: Periodontal infections and cardiovascular disease: The heart of the matter. J Am Dent Assoc 2006, 137(Suppl):14S$20 \mathrm{~S}$.

6. Baldassarre D, Veglia F, Gobbi C, Gallus G, Ventura A, Crepaldi G, Fisicaro M, Rimondi S, Ricci G, Mancini M, et al: Intima-media thickness after pravastatin stabilizes also in patients with moderate to no reduction in LDL-cholesterol levels: the carotid atherosclerosis Italian ultrasound study. Atherosclerosis 2000, 151(2):575-583.

7. Hujoel PP: Destructive periodontal disease and tobacco and cannabis smoking. JAMA 2008, 299(5):574-575.

8. Thomson WM, Poulton R, Broadbent JM, Moffitt TE, Caspi A, Beck JD, Welch D, Hancox RJ: Cannabis smoking and periodontal disease among young adults. JAMA 2008, 299(5):525-531.

9. Grossi SG, Zambon JJ, Ho AW, Koch G, Dunford RG, Machtei EE, Norderyd OM, Genco RJ: Assessment of risk for periodontal disease. I. Risk indicators for attachment loss. Journal of Periodontology 1994 65(3):260-267.

10. Armitage GC: Development of a classification system for periodontal diseases and conditions. Ann Periodontol 1999, 4(1):1-6.

11. Desvarieux M, Demmer RT, Rundek T, Boden-Albala B, Jacobs DRJ, Papapanou PN, Sacco RL: Relationship between periodontal disease, tooth loss, and carotid artery plaque: the Oral Infections and Vascular Disease Epidemiology Study (INVEST). Stroke 2003, 34(9):2120-2125.

12. Sacco RL, Boden-Albala B, Gan R, Chen X, Kargman DE, Shea S, Paik MC, Hauser WA: Stroke incidence among white, black, and Hispanic residents of an urban community: the Northern Manhattan Stroke Study. Am J Epidemiol 1998, 147(3):259-268.

13. Socransky SS, Smith C, Martin L, Paster BJ, Dewhirst FE, Levin AE: "Checkerboard" DNA-DNA hybridization. Biotechniques 1994, 17(4):788792.

14. Demmer RT, Kocher T, Schwahn C, Volzke H, Jacobs DR Jr, Desvarieux M: Refining exposure definitions for studies of periodontal disease and systemic disease associations. Community Dent Oral Epidemiol 2008, 36(6):493-502.

15. Carlos JP, Wolfe MD, Kingman A: The extent and severity index: a simple method for use in epidemiologic studies of periodontal disease. J Clin Periodontol 1986, 13(5):500-505.

16. Meng $\mathrm{XL}$, Rosenthal $\mathrm{R}$, Rubin D: Comparing correlated correlation coefficients. Psychological Bulletin 1992, 111:172-175.

17. Consensus report. Periodontal diseases: pathogenesis and microbial factors. Ann Periodontol 1996, 1(1):926-932.

18. Demmer RT, Papapanou PN, Jacobs DR Jr, Desvarieux M: Bleeding on probing differentially relates to bacterial profiles: the Oral Infections and Vascular Disease Epidemiology Study. J Clin Periodontol 2008, 35(6):479486.

19. Papapanou PN, Baelum V, Luan WM, Madianos PN, Chen X, Fejerskov O, Dahlen G: Subgingival microbiota in adult Chinese: prevalence and relation to periodontal disease progression. J Periodontol 1997, 68(7):651666.

20. Papapanou PN, Teanpaisan R, Obiechina NS, Pithpornchaiyakul W, Pongpaisal S, Pisuithanakan S, Baelum V, Fejerskov O, Dahlen G: Periodontal microbiota and clinical periodontal status in a rural sample in southern Thailand. Eur J Oral Sci 2002, 110(5):345-352.

21. Socransky SS, Haffajee AD, Cugini MA, Smith C, Kent RLJ: Microbial complexes in subgingival plaque. J Clin Periodontol 1998, 25(2):134-144.

22. Beck JD, Offenbacher S: Relationships among clinical measures of periodontal disease and their associations with systemic markers. Ann Periodontol 2002, 7(1):79-89.

23. Haffajee AD, Socransky SS: Microbial etiological agents of destructive periodontal diseases. Periodontol 2000 1994, 5:78-111.

24. Timmerman MF, Weijden Van der GA, Abbas F, Arief EM, Armand S, Winkel EG, Van Winkelhoff AJ, Velden Van der U: Untreated periodontal disease in Indonesian adolescents. Longitudinal clinical data and prospective clinical and microbiological risk assessment. J Clin Periodontol 2000, 27(12):932-942.

25. Timmerman MF, Weijden Van der GA, Arief EM, Armand S, Abbas F, Winkel EG, Van Winkelhoff AJ, Velden Van der U: Untreated periodontal disease in Indonesian adolescents. Subgingival microbiota in relation to experienced progression of periodontitis. J Clin Periodontol 2001, 28(7):617-627.
26. Velden Van der U, Abbas F, Armand S, Loos BG, Timmerman MF, Weijden Van der GA, Van Winkelhoff AJ, Winkel EG: Java project on periodontal diseases. The natural development of periodontitis: risk factors, risk predictors and risk determinants. J Clin Periodontol 2006, 33(8):540-548

27. Machtei EE, Hausmann E, Dunford R, Grossi S, Ho A, Davis G, Chandler J, Zambon J, Genco RJ: Longitudinal study of predictive factors for periodontal disease and tooth loss. J Clin Periodontol 1999, 26(6):374-380.

28. van Winkelhoff AJ, Loos BG, Reijden van der WA, Velden van der U: Porphyromonas gingivalis, Bacteroides forsythus and other putative periodontal pathogens in subjects with and without periodontal destruction. J Clin Periodontol 2002, 29(11):1023-1028.

29. Socransky SS, Haffajee AD: Evidence of bacterial etiology: a historical perspective. Periodontol 2000 1994, 5:7-25.

30. Haffajee AD, Socransky SS: Introduction to microbial aspects of periodontal biofilm communities, development and treatment. Periodontol 2000 2006, 42:7-12.

31. Moore WE, Moore LV: The bacteria of periodontal diseases. Periodontol 2000 1994, 5:66-77.

32. Feng $Z$, Weinberg $A$ : Role of bacteria in health and disease of periodontal tissues. Periodontol 2000 2006, 40:50-76.

\section{Pre-publication history}

The pre-publication history for this paper can be accessed here:http://www biomedcentral.com/1471-2288/10/2/prepub

doi:10.1186/1471-2288-10-2

Cite this article as: Demmer et al:: Evaluating clinical periodontal measures as surrogates for bacterial exposure: The Oral Infections and Vascular Disease Epidemiology Study (INVEST). BMC Medical Research Methodology 2010 10:2.

\section{Publish with Biomed Central and every scientist can read your work free of charge}

"BioMed Central will be the most significant development for disseminating the results of biomedical research in our lifetime. "

Sir Paul Nurse, Cancer Research UK

Your research papers will be:

- available free of charge to the entire biomedical community

- peer reviewed and published immediately upon acceptance

- cited in PubMed and archived on PubMed Central

- yours - you keep the copyright
BioMedcentral 